$17^{\circ} \cdot 0$ at Moyeni, Basutoland, on August 23. The mean yearly value of the absolute maxima was $86^{\circ} \cdot 9$, and of the corresponding minima $4 \mathrm{I}^{\circ} \cdot 6$. The mean temperature for the year was $0^{\circ} .9$ below the average. The stormiest month was October, and the calmest was April.

We have also received the official meteorological yearbooks for South Australia (1904) and Mysore (1905). Both of these works contain valuable means for previous years.

Forty Years of Southern New Mexico Climate.-Bulletin No. 59 of the New Mexico College of Agriculture contains the meteorological data recorded at the experimental station from 1892 to 1905 inclusive, together with results of temperature and rainfall observations at other stations in the Mesilla Valley for most of the years between $185^{I}$ and I 890 , published some years ago by General Greely in a "Report on the Climate of New Mexico." The station is situated in lat. $32^{\circ} 15^{\prime} \mathrm{N}$., long. $106^{\circ} 45^{\prime} \mathrm{W}$. , and is 3868 feet above sea-level. The data have a general application to those portions of southern New Mexico with an altitude less than 4000 feet. The mean annual temperature for the whole period was $61^{\circ} \cdot 6$, mean maximum (fourteen years) $76^{\circ} .8$ mean minimum $4 \mathrm{r}^{\circ} \cdot 4$, absolute maximum $106^{\circ}$ (which occurred several times), absolute minimum $I^{\circ}$ (December, 1895 ). The mean annual rainfall was 8.8 inches; the smallest yearly amount was 3.5 inches, in 1873, the largest 17.1 inches, in 1905. Most of the rain falls during July, August, and September. The relative humidity is low, the mean annual amount being about $5^{1}$ per cent. The bulletin was prepared by $\mathrm{J}$. D. Tinsley, vice-director of the station.

Meteorological Obscrvations in Germany. - The results of the observations made under the system of the Deutsche Seewarte, Hamburg, for 1905 , at ten stations of the second order, and at fifty-six storm-warning stations, have been received. This is the twenty-eighth yearly volume published by the Seewarte, and forms part of the series of German meteorological year-books. We have frequently referred to this excellent series, and the volume in question is similar in all respects to its predecessors; it contains most valuable data relating to the North Sea and Baltic coasts. We note that the sunshine at Hamburg was only 29 per cent. of the possible annual amount, and that there were $\mathrm{IO}_{3}$ sunless days; the rainfall was 25.9 inches, the rainy days being 172 in number.

\section{VOX POPULI}

$\mathrm{I}^{\mathrm{N}}$ these democratic days, any investigation into the trustworthiness and peculiarities of popular judgments is of interest. The material about to be discussed refers to a small matter, but is much to the point.

A weight-judging competition was carried on at the annual show of the West of England Fat Stock and Poultry Exhibition recently held at Plymouth. A fat ox having been selected, competitors bought stamped and numbered cards, for $6 d$. each, on which to inscribe their respective names, addresses, and estimates of what the ox would weigh after it had been slaughtered and "dressed." Those who guessed most successfully received prizes. About 800 tickets were issued, which were kindly lent me for examination after they had fulfilled their immediate purpose. These afforded excellent material. The judgments were unbiassed by passion and uninfluenced by oratory and the like. The sixpenny fee deterred practical joking, and the hope of a prize and the joy of competition prompted each competitor to do his best. The competitors included butchers and farmers, some of whom were highly expert in judging the weight of cattle; others were probably guided by such information as they might pick up, and by their own fancies. The average competitor was probably as well fitted for making a just estimate of the dressed weight of the ox, as an average voter is of judging the merits of most political issues on which he votes, and the variety among the voters to judge justly was probably much the same in either case.

After weeding thirteen cards out of the collection, as being defective or illegible, there remained 787 for discussion. I arrayed them in order of the magnitudes of the estimates, and converted the cut., quarters, and lbs. in which they were made, into lbs., under which form they will be treated.

$$
\text { NO. I 949, VOI. } 751
$$

Distribution of the estimates of the dressed weight of a particular living ox, made by 787 different persons.

\begin{tabular}{|c|c|c|c|c|}
\hline \multirow{2}{*}{$\begin{array}{l}\text { Degrees of } \\
\text { the length of } \\
\text { Array o } 0^{\circ}-100^{\circ}\end{array}$} & \multirow[b]{2}{*}{$\begin{array}{l}\text { Estimates } \\
\text { in lbs. }\end{array}$} & \multicolumn{2}{|c|}{ Centiles } & \multirow{2}{*}{$\begin{array}{c}\text { Excess of } \\
\text { Observed over } \\
\text { Normal }\end{array}$} \\
\hline & & $\begin{array}{c}\text { Observed } \\
\text { deviates from } \\
\text { t207 lbs. }\end{array}$ & $\begin{array}{l}\text { Normal } \\
\text { p.e }=37\end{array}$ & \\
\hline 5 & 1074 & -133 & -90 & +43 \\
\hline 10 & 1109 & -98 & -70 & +28 \\
\hline 15 & I 126 & $-8 I$ & -57 & +24 \\
\hline 20 & 1148 & -59 & -46 & +13 \\
\hline$q_{1} 25$ & I 162 & -45 & -37 & +8 \\
\hline 30 & I 774 & -33 & -29 & +4 \\
\hline 35 & IISI & -26 & $-2 \mathrm{I}$ & +5 \\
\hline 40 & I1 88 & -19 & $-\mathrm{I}_{4}$ & +5 \\
\hline 45 & I 197 & - I0 & -7 & +3 \\
\hline$m 50$ & 1207 & 0 & 0 & \\
\hline 55 & I 214 & +7 & +7 & 0 \\
\hline 60 & 1219 & +12 & +14 & -2 \\
\hline 65 & 1225 & +18 & +21 & -3 \\
\hline 70 & 1230 & +23 & +29 & -6 \\
\hline$q_{3} 75$ & 1236 & +29 & +37 & -8 \\
\hline 80 & 1243 & +36 & $+4 i$ & -10 \\
\hline 85 & 1254 & +47 & +57 & -10 \\
\hline 90 & 1267 & +52 & +70 & -18 \\
\hline 95 & 1293 & +86 & +90 & -4 \\
\hline
\end{tabular}

$q_{1}, q_{3}$, the first and third quartiles, stand at $25^{\circ}$ and $75^{\circ}$ resp scively. $m$, the median or middlemost value, stands at $50^{\circ}$.

The dressed weight proved to be rigs lbs.

According to the democratic principle of "one vote one value," the middlemost estimate expresses the vox populi, every other estimate being condemned as too low or too high by a majority of the voters (for fuller explanation see "One Vote, One Value," Nature, February 28 , p. 4I4). Now the middlemost estimate is $1207 \mathrm{lb}$., and the weight of the dressed ox proved to be $11981 \mathrm{~b}$.; so the vox populi was in this case $9 \mathrm{lb}$., or 0.8 per cent. of the whole weight too high. The distribution of the estimates about their middlemost value was of the usual type, so far that they clustered closely in its neighbourhood and became rapidly more sparse as the distance from it increased.

Diagram, from the tabular values.

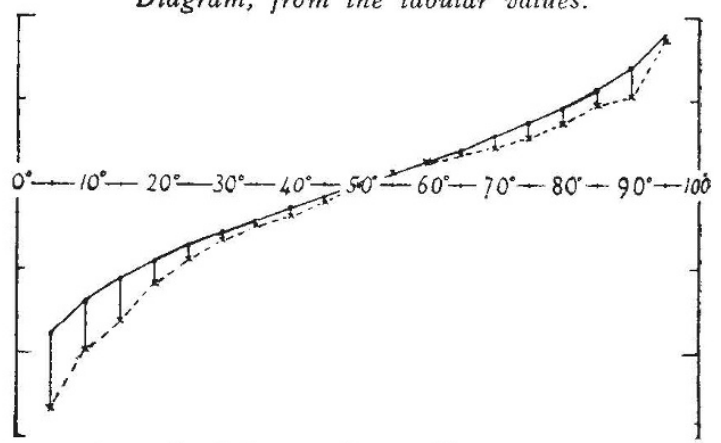

The eontinuous line $\mathrm{i}$ - the normal curve $\mathrm{u}$ ith p.e. $=37$.

I he broken line is drawn from the observations.

the lines connecting them show the differences between the observed and the normal.

But they were not scattered symmetrically. One quarter of them deviated more than $45 \mathrm{lb}$. above the middlemost ( 3.7 per cent.), and another quarter deviated more than $29 \mathrm{lb}$. below it $(2.4$ per cent.), therefore the range of the two middle quarters, that is, of the middlemost half, lay within those limits. It would be an equal chance that the estimate written on any card picked at random out of the collection lay within or without those limits. In other words, the "probable error" of a single observation may be reckoned as $\frac{1}{2}(45+29)$, or $37 \mathrm{lb}$. (3.I per cent.). Taking this for the p.e. of the normal curve that is best adapted for comparison with the observed values, the results are obtained which appear in above table, and graphically in the diagram. 
The abnormality of the distribution of the estimates now becomes manifest, and is of this kind. The competitors may be inagined to have erred normally in the first instance, and then to have magnified all errors that were negative and to have minified all those that were positive. The lower half of the "observed" curve agrees for a large part of its range with a normal curve having the p.e. $=45$, and the upper half with one having its p.e. $=29$. I have not sufficient knowledge of the mental methods followed by those who judge weights to offer a useful opinion as to the cause of this curious anomaly. It is partly a psychological question, in answering which the various psychophysical investigations of Fechner and others would have to be taken into account. Also the anomaly may be partly due to the use of a small variety of different methods, or formulæ, so that the estimates are not homogeneous in that respect.

It appears then, in this particular instance, that the vox populi is correct to within I per cent. of the real value, and that the individual estimates are abnormally distributed in such a way that it is an equal chance whether one of them, selected at random, falls within or without the limits of -3.7 per cent. and +2.4 per cent. of their middlemost value.

This result is, I think, more creditable to the trustworthiness of a democratic judgment than might have been expected.

The authorities of the more important cattle shows might do service to statistics if they made a practice of preserving the sets of cards of this description, that they may obtain on future occasions, and loaned them under proper restrictions, as these have been, for statistical discussion. The fact of the cards being numbered makes it possible to ascertain whether any given set is complete.

Francis Galton.

\section{THE WORK OF THE OPTICAL SOCIETY. ${ }^{1}$}

THOUGH it is perhaps seldom that the Transactions of the Optical Society contain much record of original research, yet they often furnish matter of considerable value to the practical optician, and will usually be found to contain more than one paper of importance to the student of optics. The first paper in the present volume will have interest for many readers. It is a short and clear statement, by one well qualified to judge, Mr. W. A. Dixey, of the case for the use of periscopic lenses in spectacles. A periscopic lens, as defined by Mr. Dixey, is one through which its wearer can look obliquely as well as directly without his vision being impaired by radial astigmatism. The result is attained either by deepening the curves of the lens so as to produce an approximation to a sphere the centre of which coincides with the centre of rotation of the eye, or by the use of toric lenses. A careful reading of Mr. Dixey's paper would probably lead many wearers of spectacles to pay another visit to the optician.

The paper by Mr. Theodore Brown, on direct stereoscopic projection, is of special interest. It describes an ingenious device for obtaining stereoscopic effects in pictures projected on a screen, of which probably more will be heard. The argument is that in binocular vision the stereoscopic effect is due to the fact that the two images of the same object in the two eyes are not formed in similar positions on the relina, and that it should be possible to produce stereoscopic effects even when one eye only is used if by some means two simultaneous pictures can be formed on the retina in appropriate positions. Owing to the permanence of retinal impressions, this can be effected by throwing on the screen with rapid alternation the two stereoscopic pictures in somewhat displaced positions. The displacement is produced by giving a motion to the projection camera, and the stereoscopic can be combined with the "bioscopic" effect by the use of a kinematograph mechanism. It is clear from the paper and the discussion that further perfection of detail is necessary to produce completely satisfactory results, but there seems no reason why the difficulties should not be overcome. There is, I Transactions of the Optical Society, London, Session r904-5. Pp. 93. Price ros.

NO. I 949, VOL. 75$]$ however, some reason for suggesting that perhaps a oneeyed spectator would be the most appreciative.

In "A Method of Testing Prisms," Mr. S. D. Chalmers, the head of the optical department at the Northampton Institute, suggests some useful applications of the method of auto-collimation for the determination of the angles of prisms to the highest possible accuracy. We would direct attention especially to the procedure suggested for the measurement of one of the angles of a $60^{\circ}$ prism $\mathrm{ABC}$. Rays entering perpendicular to the face $\mathrm{BC}$ are totally reflected at $30^{\circ}$ from $\mathrm{CA}$ or $\mathrm{AB}$, and reflected normally at $\mathrm{AB}$ or $\mathrm{CA}$, emerging again approximately perpendicular to BC. From the separation of the incident and emergent rays the error in the angle $\mathrm{A}$ can be determined. Only one reflection takes place normally at a glass-air surface, and there is, therefore, no difficulty in seeing the image. Simultaneous observation of the direct reflection from $B C$ aids in setting the prism. A similar method can readily be applied in other instances, and the figures in the paper suggest at once the procedure in the cases which occur most frequently. The lack of parallelism in plane paralle glass can also be tested in this manner. Rigidity is, of course, essential in the apparatus to be employed for the observations, and Mr. Chalmers has obviously given some attention to details in the construction of a suitable autocollimator; drawings or diagrams of this would have added to the value and interest of the paper.

Mr. L. W. Phillips, student member, in a paper on the measurement of absorption in tinted glasses, describes some observations on the absorption of light by coloured glasses, such as are used for spectacles, a "fliciser" photometer being employed for the measurements. The method does not admit of great accuracy, but is no doubt useful within certain limits for rough work of the kind suggested. It raises, however, some vexed questions as to the photometry of coloured lights, and some points of interest in relation to the "flicker" instrument were brought up in the discussion by Dr. Garnett and others.

A presidential address by Prof. Silvanus P. Thompson, on the early literature of optics, demands no more than passing mention here, great though its interest must have been to those who had the pleasure of listening to it. The volume closes with a contribution by Mr. A. T. Bull, entitled "Some Notes on the Nature of Vision." The paper, being essentially of the nature of notes, passes rapidly over many points of interest in connection with the mechanism of vision and the molecular and other phenomena accompanying it. Various topics are thus touched on, from the accuracy of the photometric results obtained with rotating sectors to the difficulties yet re. quiring explanation on the Darwinian theory in regard to the process of evolution of vision. The notes are sugsestive, but would make more interesting reading if less loosely put together.

We would venture to suggest, in conclusion, that the editing of the volume leaves something to be desired. It may be possible to interpret such phrases as "beep lenses on the Willaston principle," and to escape being deceived by the "dissimulation" of a photochemical body, but the fact that Lewis Carroll was a mathematician does not sufficiently justify such imitation of his playful extravagances in a scientific journal; and the volume is marred by many such misprints.

\section{THE COMPRESSIBILITY OF CRYSTALLINE ROCKS. ${ }^{1}$}

THE latter-day revival of interest in geological physics has led to a keen demand for experimental data, the absence of which has hitherto rendered futile most speculation in this domain. Our almost complete ignorance of the simplest physical constants of rocks and the rockforming minerals is easy to account for. The kind of investigation required is both difficult and laborious, calling for skill and practice as well as the appliances of a well-equipped physical laboratory; and the geologist may lack either the capacity or the opportunity for such re1 "An Investigation into the Elastic Constan!s of Rocks, more Fspecially with Reference to Cut ic Compressibility." By Prof. Frank D. Adarns and Prof. Ernest G. Ccker. Pp. 6g. (Washington, D.C. : Carnegie Institution, I9ว6.) 